\title{
Optimization of Photocatalytic Degradation of Phenol Using Simple Photocatalytic Reactor
}

\author{
Innocent Udom1, Philip D. Myers ${ }^{1,2}$, Manoj K. Ram ${ }^{1}$, A. F. Hepp ${ }^{3}$, Edikan Archibong2, \\ Elias K. Stefanakos ${ }^{1,4}$, D. Yogi Goswami1,2 \\ ${ }^{1}$ Clean Energy Research Center, College of Engineering, University of South Florida, Tampa, USA \\ ${ }^{2}$ Department of Chemical and Biomedical Engineering, University of South Florida, Tampa, USA \\ ${ }^{3}$ NASA Glenn Research Center, Research and Technology Directorate, Cleveland, USA \\ ${ }^{4}$ Department of Electrical Engineering, University of South Florida, Tampa, USA \\ Email: $\underline{\text { mkram@usf.edu }}$
}

Received 7 June 2014; revised 25 July 2014; accepted 11 August 2014

Copyright (C) 2014 by authors and Scientific Research Publishing Inc.

This work is licensed under the Creative Commons Attribution International License (CC BY).

http://creativecommons.org/licenses/by/4.0/

(c) (i) Open Access

\section{Abstract}

The phenol photocatalytic degradation was investigated using heterogeneous catalyst Ag-doped ZnO nanowires under UV irradiation. Ag-ZnO nanowires were immobilized on borosilicate glass via a simple hydrothermal technique. Preliminary photodegradation studies were performed with Ag-ZnO nanowires at various concentrations of phenol $(10-60 \mathrm{mg} / \mathrm{L})$ at undiluted $\mathrm{pH}$. After determination of the optimal initial concentration $(30 \mathrm{mg} / \mathrm{L})$, additional parameters including $\mathrm{pH}$ and light intensity were investigated to optimize photodegradation of phenol for large-scale application. The experimental results illustrate that the kinetics of degradation of phenol are pseudo-first order. Based on the relationship, experimental model and empirical correlation were generated and compared for validity. The experimental data were found to fit a cubic model (linear in UV irradiation intensity, $I$, and cubic in $\mathrm{pH}$ ), over ranges of 10 - $60 \mathrm{~W}$ (UV lamp power) and 2.7 - $11.0(\mathrm{pH})$ with a coefficient of determination $\left(R^{2}\right)$ of 0.9934 . This model, of the form $K(I, \mathrm{pH})=$ $c_{00}+c_{10} I+c_{01} \mathrm{pH}+c_{11} I \mathrm{pH}+c_{02} \mathrm{pH}^{2}+c_{12} \mathrm{IpH}^{2}+c_{03} \mathrm{pH}^{3}$ was found to yield a better fit than simpler (quadratic) or more complex (quartic) polynomial-based models considered. The model parameters $c_{i j}$ and corresponding $95 \%$ confidence intervals were obtained.

\section{Keywords}

Ag-ZnO Nanowires, Photocatalyst, Photodegradation, Phenol, Model 


\section{Introduction}

Phenols are among the numerous organic pollutants and toxic chemicals discharged into the aquatic environment that cause negative flavor and unpleasant odors in portable water. Phenols are generally bio-recalcitrant and stem from industrial sources, including pesticide, paint, petroleum and petrochemical industries, to mention a few [1]-[3]. Despite their low dosage, these pollutants may pose a major health hazard due to their mutagenicity and genotoxicity. Phenols are mutagenic and may be absorbed through the skin and harmful even at low dosage [4] [5]. Hence, degradation of phenol is important. A large body of researchers have worked on a number of remediation processes and came up with several chemical [6]-[8], biological [9], and physical [10] [11] processes. Since the application of these processes involved high costs and could possibly introduce more contaminants into the environment, developing energy efficient and "green" technologies to minimize these limitations while producing the desired complete mineralization of organic contaminants is of particular importance. Advanced oxidation processes (AOP) - a process of mineralization of organic compounds into simple products such $\mathrm{CO}_{2}$ and water, have emerged as the most promising technology in the last few decades [12]-[14]. Among the semiconductors for AOPs, $\mathrm{TiO}_{2}$ and $\mathrm{ZnO}$ are the most often studied materials and employed due to their ability to produce hydroxyl radicals to destroy numerous types of organic contaminants [15]. Moreover, they are nontoxic, cheap and abundant.

Researchers and scientists have investigated the photodegradation of phenol using metal-doped photocatalysts, for example, Grabowska et al. [1] reported a three times higher photodegradation with 3\% $\mathrm{W}-\mathrm{TiO}_{2} \mathrm{compared} \mathrm{to}$ $\mathrm{TiO}_{2}$ nanoparticles under irradiation of visible light. In the presence of $\mathrm{W}-\mathrm{TiO}_{2}$ under visible light phenol was degraded to catechol and muconicaldehyde. Devi and Rajashekhar [16] doped $\mathrm{TiO}_{2}$ with $\mathrm{N}_{2}$ gas or the mineralized phenol under visible and UV light irradiation. Higher photodegradation of phenol was achieved with $0.15 \%$ dopant concentration compared to sol-gel $\mathrm{TiO}_{2}$ under UV/solar irradiation than using hydrogen peroxide and ammonium peroxydisulfate as acceptors. Furthermore, Kavitha and Palanivelu [17] conducted a batch study using phenol as a model pollutant in industrial water to optimize parameters such as $\mathrm{pH}$, hydrogen peroxide and ferrous oxide concentrations affecting Fenton-related oxidation reaction. The highest photodegradation efficiencies were Fenton (41\%), solar (96\%) and UV-Fenton (97\%) processes.

The optimization of photodegradation of phenol with immobilized $\mathrm{ZnO}$-Ag nanowires using a simple photocatalytic rector under UV irradiation has not been shown in literature.

\section{Experimental}

\subsection{Materials}

The analytical grades chemicals are used without further purification process. Silver nitrate $\left(\mathrm{AgNO}_{3}, 99.9 \%\right)$ was purchased from Sigma-Aldrich and used to provide doping, zinc acetate $\left(\mathrm{Zn}\left(\mathrm{CH}_{3} \mathrm{COO}\right)_{2}, 99.9 \%\right)$ was procured from Fisher Scientific. Sodium hydroxide (NaOH, 44\%) and hydrochloric acid (37\%) were also obtained from Fisher Scientific. The double-distilled water was employed to prepare the desired phenol concentration.

\subsection{Photoreactor}

The various experiments were carried out in a laboratory fabricated aluminum photoreactor with dimension of $38.1 \mathrm{~cm}$ (15 in) long by $5.1 \mathrm{~cm}$ (2 in) wide by $2.5 \mathrm{~cm}$ (1 in) high. Aluminum sheet of $5.6 \mathrm{~cm}$ was used to build this reactor. A peristaltic pump (Masterflex L/S, $160 \mathrm{ml} / \mathrm{min}$ flow) was connected and pumped water from the glass beaker to the reactor. The water circulated through the reactor and returned to the beaker continuously during the experiment. The reactor system contained a lid, a UVA transparent glass, which was employed to prevent evaporation. The vessel top contains a light source. A lamp box which consisted of two Southern New England Ultraviolet Company Rayonet RPR-3500 A UVA lamps (30.5 cm long) was used; the lamps provided irradiation in the UVA range of 350 - $400 \mathrm{~nm}$. Other information about the photoreactor can be found at Udom et al. [18]. The light intensity at the surface of the reactor in the photoreactor was measured by an LI-COR pyranometer.

\subsection{Preparation of Ag-Zn NWs}

A seed solution of equimolar ratio $(5 \mathrm{mM})$ of $\mathrm{AgNO}_{3}$ and $\mathrm{Zn}\left(\mathrm{CH}_{3} \mathrm{COO}\right)_{2}$ in ethanol was prepared; a $1.25 \mathrm{ml}$ aliquot of this solution was placed on a substrate. An aliquot of $0.5 \mathrm{ml}$ seed particle solution was placed on the 
substrate (borosilicate glass) and randomly tilted in different directions to ensure uniform distribution. The seeded substrate was dried in an oven at $100^{\circ} \mathrm{C}$ for $10 \mathrm{~min}$ to remove moisture and another $30 \mathrm{~min}$ at $350^{\circ} \mathrm{C}$ to remove unreacted organic matter. After cooling, the substrate was placed in a reactor containing the growth solution, and stirred for 2 hours at $90^{\circ} \mathrm{C}$. After this step, the substrate was rinsed with water and oven dried at $100^{\circ} \mathrm{C}$ for $10 \mathrm{~min}$. and $350^{\circ} \mathrm{C}$ for $30 \mathrm{~min}$.

\subsection{Procedure and Analysis}

The reaction mixture was placed for 30 min in the dark to establish adsorption equilibrium of phenol solution on the photocatalyst and then UV irradiated for $150 \mathrm{~min}$. At certain interval, aliquot (5 ml) were collected and analyzed to assess photodegradation. A gas chromatograph (GC) with flame ionization detector (FID) via the head space method was used for phenol analysis. The GC used was SRI8600 with a $30 \mathrm{~m}$ DB-624 capillary column. To evaluate the impact of initial concentration and catalyst dosage on photocatalytic efficiency, experiments were performed at initial phenol concentration from $10-60 \mathrm{mg} / \mathrm{L}$ and catalyst loading $250-7500 \mathrm{mg} / \mathrm{L}$. After determination of the optimal values, additional parameters including $\mathrm{pH}$ and light intensity were investigated for optimization and a model was established. Diluted $\mathrm{NaOH}$ and $\mathrm{HCl}$ were used to adjust $\mathrm{pH}$ within range 2.7 to 11 and was measured using Orion 5 Star ThermoScientific. The unadjusted initial phenol solution measured pH 8.2.

\section{Result and Discussion}

\subsection{Effect of Initial Phenol Concentration}

The effect of initial phenol concentration to the removal rate equation is vital for the optimization of the various concentration of phenol and development of a model. The reaction rate constant, $\mathrm{K}$, decreases as the initial concentration increases while holding other parameters constant. This could be due to saturation of active sites on the photocatalyst by intermediates, hereby creating fewer sites for adsorption and creation of hydroxyl ions. Unlike other contaminants, the transmittance of UV light through the aqueous solution of phenol, due to its transparency, does not contribute to the decrease in rate constant. As observed in the Figure 1, the empirical first-order relationship of different initial concentrations of phenol to the reaction rate constant is illustrated. Shukla et al. [19] examined the role of initial concentration (12.5 - $37.5 \mathrm{ppm})$ in the photodegradation of phenol. Optimum value was achieved at $12.5 \mathrm{ppm}$, under the condition studied $(\mathrm{ZnO}=0.4 \mathrm{~g} / \mathrm{L}$, persulfate $=2 \mathrm{~g} / \mathrm{L}$ ad power $=330 \mathrm{~W}$ ). Pardeshi and Patil have shown a decrease in phenol for the increase in concentration range from 25 - $300 \mathrm{mg} / \mathrm{L}$ [20]. However, less number of $\mathrm{OH}$ and $\mathrm{O}_{2}$ radicals are available due to the constant reaction condition where more substrates molecules are adsorbed on the surface on the photocatalyst.

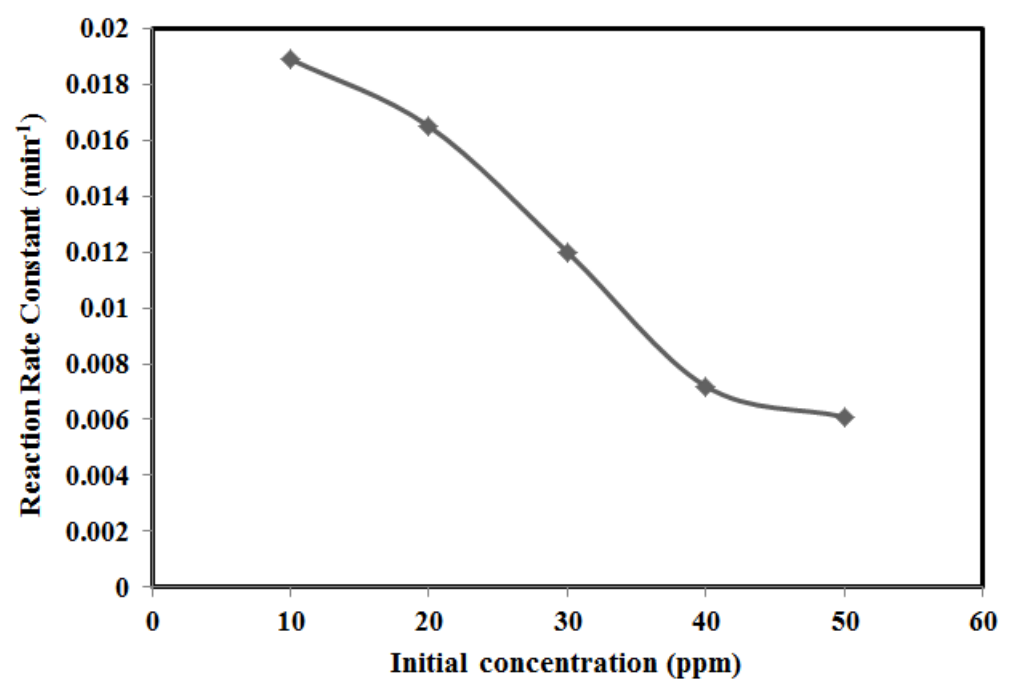

Figure 1. The effect of the initial concentration of phenol on reaction rate constant. Ag-ZnO NW $=500 \mathrm{mg} / \mathrm{L}, \mathrm{T}=295 \pm 2 \mathrm{~K}, \mathrm{pH}=8.7$, Light intensity $=60$ $\mathrm{W} / \mathrm{m}^{2}$. 


\subsection{Effect of UV Intensity}

The photocatalytic degradation of organic compound is dependent effect of UV light intensity where the UV irradiation creates the photons needed to move electrons in the bands (valence band to conduction band) of the photocatalyst semiconductor. The irradiation produces the energy to drives the overall reaction, thus the reaction rate constant depends on the intensity of the irradiation. The rate of photocatalytic mineralization of phenol increases as more photons (increasing radiation) of sufficient energy reach the surface of the catalyst. The light intensity plays a key role in photochemical reaction for initiating the electron-hole formation. Chiou et al. [21] examined the UV light intensity (20 - $40 \mathrm{~W}$ ) effect on the phenol degradation. Under UV irradiation over $\mathrm{TiO}_{2}$ photocatalyst, the reaction rate constant was $0.0083,0.012$ and $0.031 \mathrm{~min}^{-1}$ with light intensity of 20, 100 and $400 \mathrm{~W}$, respectively. A more or less linear correlation was established between the rate constants and light intensity. Ollis et al. [22] have studied the degradation of organic pollutants (benzene and perchloroethylene) in a system of $\mathrm{UV} / \mathrm{TiO}_{2}$ at intensity $\leq 25 \mathrm{~mW} / \mathrm{cm}^{2}$ and further, shown that the reaction rate was independent of the light intensity for higher intensity.

In this study, varying intensities of UV radiation (10,30, and $60 \mathrm{~W}$ ) were used with Ag-ZnO NWs to catalyze the degradation of phenol in water at varying $\mathrm{pH}(2.7,5.0,8.1$, and 11.0). The data are plotted in Figure 2 as reaction rate constant versus UV lamp intensity. Approximate linearity with respect to lamp intensity is observed at each $\mathrm{pH}$ level considered.

\subsection{Effect of pH}

The role of $\mathrm{pH}$ on the efficiency of photocatalytic degradation of phenol was investigated in the $\mathrm{pH}$ range 2.7 11; the results are plotted in Figure 3. The three sets of data, reaction rate versus $\mathrm{pH}$ level, correspond to data collected at constant UV lamp intensity $(10,30$, or $60 \mathrm{~W})$. While the choice of interpolation curve is somewhat arbitrary (for each set of data, a cubic polynomial is fit to the data points), each curve suggests a maximum reaction rate at a pH level of approximately 5.5 - 6.0. At $\mathrm{pH}(5-6)$, most of the phenol molecules are adsorbed on the surface of the photocatalyst due to the undissociated nature of the phenol thereby producing higher photocatalytic efficiency. The surface of the photocatalyst is negatively charged, at higher $\mathrm{pH}$ (higher alkalinity), phenolate intermediates may be repelled away from the catalyst surface thereby opposing adsorption of contaminant molecules. Thus, lower degradation of phenol is observed in alkaline environments. Similar results were reported by Pardeshi and Patil [20] and Lathasree [23]. Akbar and Onar [24] studied the effect of pH on the photodegradation of phenol at the $\mathrm{pH}$ range 3 - 8. At mildly acidic $(\mathrm{pH} 5)$ condition, the highest photocatalytic activity was observed, while addition of an oxidant/electron acceptor $\left(\mathrm{H}_{2} \mathrm{O}_{2}\right)$ to the system increased phenol degradation to $99.2 \%$.

\subsection{Empirical Correlation}

In formulation of a complete model equation for the degradation of phenol by Ag- $\mathrm{ZnO}$ nanowires at varying $\mathrm{pH}$ and UV intensities, the authors initially examined the data and their dependence on each variable separately, as depicted in Figure 2 and Figure 3. As can be seen in Figure 2, the dependence on UV lamp intensity is adequately modeled by a linear equation; that is:

$$
K(I)=a_{1} I+a_{0}
$$

here, $I$ is the UV lamp intensity, in $\mathrm{W}$, and $a_{i}$, with units of $\mathrm{W}^{-i} \mathrm{~min}^{-1}$, represents the constants that fit the empirical model to the collected data. Similarly, the data suggest that the $\mathrm{pH}$ dependence can be captured by a polynomial, albeit with more terms. In other words:

$$
K(\mathrm{pH})=\sum_{i=0} b_{i} \mathrm{pH}^{i}
$$

For the case of a cubic polynomial, for instance:

$$
K(\mathrm{pH})=b_{3} \mathrm{pH}^{3}+b_{2} \mathrm{pH}^{2}+b_{1} \mathrm{pH}+b_{0}
$$

here, $b_{i}$ (units of $\min ^{-1}$ ) likewise represents the constants of the empirical model.

In fitting the multivariate model, the most obvious choice for a mathematical description of the data would be a similar polynomial, which can be formulated as follows. 


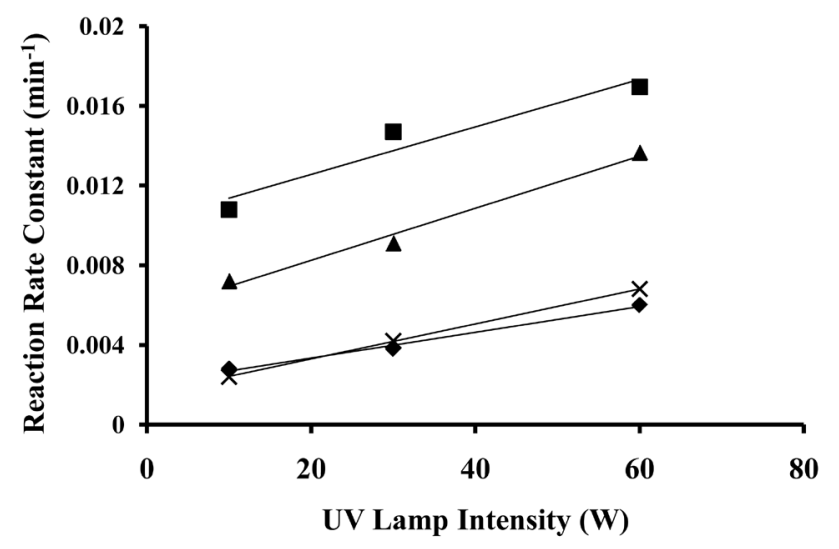

Figure 2. The effect of the UV light intensity on reaction rate constant; Ag$\mathrm{ZnO} \mathrm{NW}=500 \mathrm{mg} / \mathrm{L}, \mathrm{T}=295 \pm 2 \mathrm{~K}$, initial concentration $=30 \mathrm{ppm}$, and $\mathrm{pH}=$ $2.7(\bullet), 5.0(\bullet), 8.7(\boldsymbol{\Delta})$, and $11(\times)$.

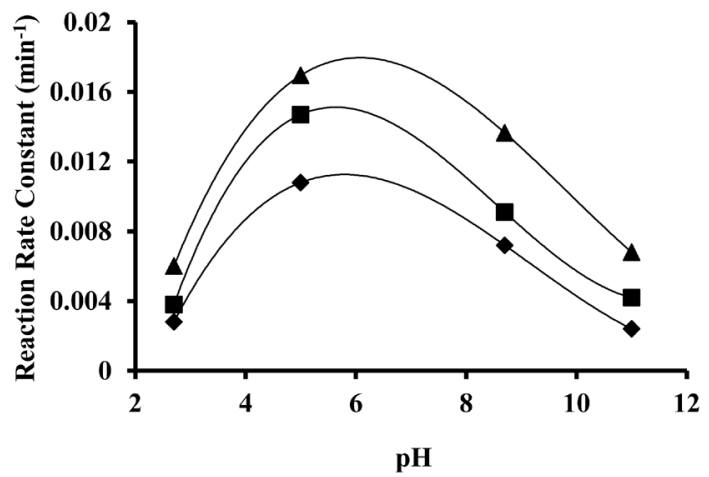

Figure 3. The effect of $\mathrm{pH}$ on reaction rate constant; Ag-ZnO NW $=500 \mathrm{mg} / \mathrm{L}$, $\mathrm{T}=295 \pm 2 \mathrm{~K}$, initial concentration $=30 \mathrm{ppm}$, and UV lamp intensity $=10 \mathrm{~W}$ $(\diamond), 30 \mathrm{~W}(\mathbf{\bullet})$, and $60 \mathrm{~W}(\boldsymbol{\Delta})$.

$$
K(I, \mathrm{pH})=\sum_{i=0} \sum_{j=0} c_{i j} I^{i} \mathrm{pH}^{j}
$$

In this case, $c_{i j}$ (units of $\mathrm{W}^{-i} \mathrm{~min}^{-1}$ ) represents the constants of the multivariate model. In fleshing out the form of the final model, it is useful to recall the linearity of the data with regard to varied UV lamp intensity; hence, in this study, we neglected any terms of quadratic or higher order in intensity (i.e., $i \leq 1$ ). Similarly, we recognize that, given that cubic polynomials capture the $\mathrm{pH}$ dependence quite well, we can neglect quartic and higher order terms in $\mathrm{pH}$ (i.e., $\quad j \leq 3$ ).

The data obtained from experiment were fitted to potential polynomial models using least-squares regression. The results of the analysis of various potential models are tabulated as Table 1. For each equation, derived constants and the corresponding coefficient of determination $\left(R^{2}\right)$ are given.

It can be seen that on the basis of the coefficient of determination, the best fit is given by the following equation:

$$
K(I, \mathrm{pH})=c_{00}+c_{10} I+c_{01} \mathrm{pH}+c_{11} I \mathrm{pH}+c_{02} \mathrm{pH}^{2}+c_{12} I \mathrm{pH}^{2}+c_{03} \mathrm{pH}^{3}
$$

This equation is plotted in Figure 4 with experimental data for comparison. It is interesting to note that the addition of the $c_{13} I_{\mathrm{pH}^{3}}$ term does nothing appreciable to improve the accuracy of the fit of the model equation. Also, the authors examined higher order polynomials with similar deficiency in accuracy: a simple quartic polynomial gives an $R^{2}$ value of 0.9866 . As such, the above equation is recommended for further design calculations and scale up of the bench scale reactor.

Finally, we consider the uncertainty in the derived model equation parameters. For the chosen equation 
Table 1. Derived model parameters and coefficient of determination for candidate model equations.

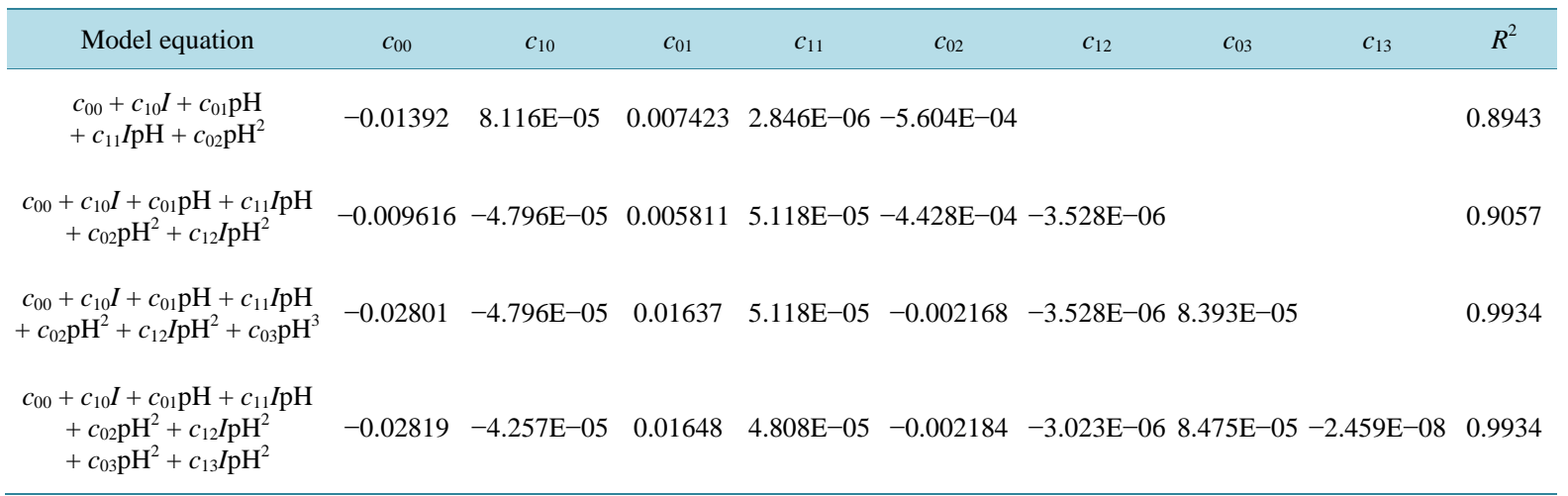

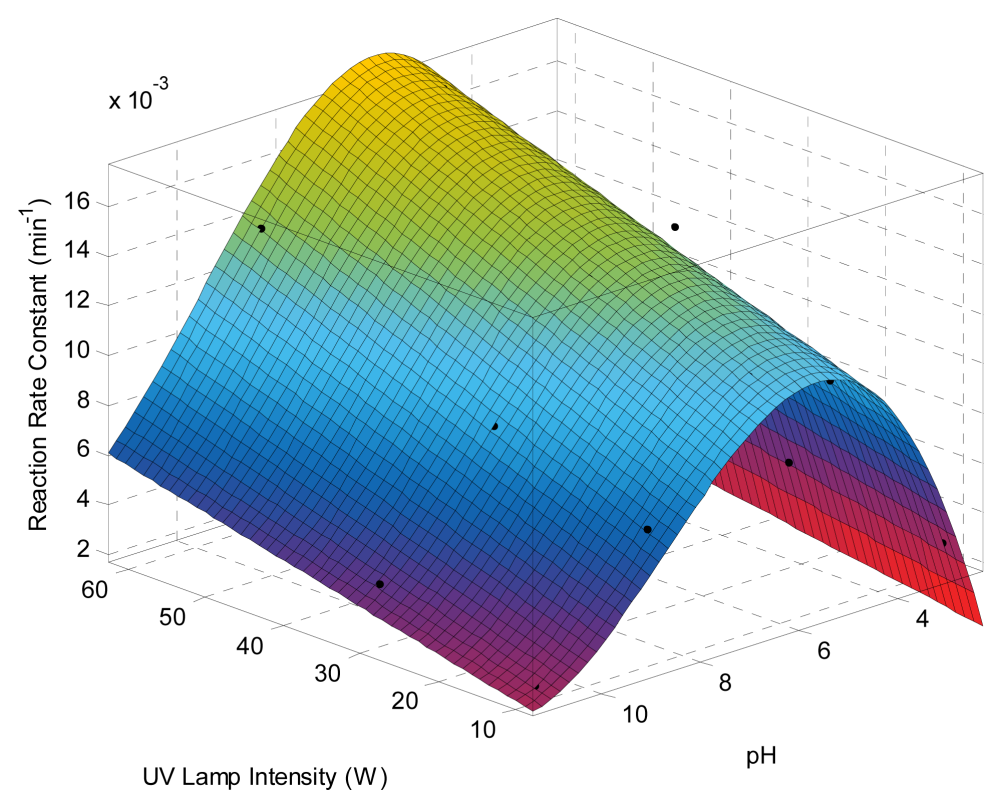

Figure 4. The recommended polynomial model equation plotted on three axes as a surface with experimental data $(\bullet)$ overlain.

$$
\left[K(I, \mathrm{pH})=c_{00}+c_{10} I+c_{01} \mathrm{pH}+c_{11} I \mathrm{pH}+c_{02} \mathrm{pH}^{2}+c_{12} I \mathrm{pH}^{2}+c_{03} \mathrm{pH}^{3}\right],
$$

95\% percent confidence intervals were generated for each equation parameter; the results are presented in Table 2. It can be seen that while a good fit was obtained, on the basis of the coefficient of determination, there is a good degree of variability over the $95 \%$ confidence intervals for most of the model parameters. It may be beneficial as a part of future investigative work to examine operating conditions of intermediate $\mathrm{pH}$ and/or UV intensity to the work considered here; by considering a greater breadth of data, a greater degree of certainty regarding the equation parameters of the resultant model may be obtained.

\section{Conclusion}

In this work, a facile hydrothermal technique was employed for immobilization of Ag-ZnO NWs on a borosilicate glass for successful degradation of phenol. From a preliminary study, an optimal initial concentration (30 mg/L) of phenol was attained. An attempt to form an overall model for the variation in phenol degradation rate for the function of intensity of UV light and $\mathrm{pH}$ level of the solution was demonstrated. For constant $\mathrm{pH}$, it was found that the reaction rate is approximately linear with respect to the intensity of UV light. For constant intensity of UV light, the reaction rate is approximately cubic in $\mathrm{pH}$. As such, a cubic model equation was derived (see Table 2) 
Table 2. Derived model equation with parameter values/95\% confidence intervals.

\begin{tabular}{|c|c|c|c|c|}
\hline \multicolumn{5}{|c|}{$c_{00}+c_{10} I+c_{01} \mathrm{pH}+c_{11} I \mathrm{pH}+c_{02} \mathrm{pH}^{2}+c_{12} I \mathrm{pH}^{2}+c_{03} \mathrm{pH}^{3}$} \\
\hline \multirow{2}{*}{$\begin{array}{c}\text { Parameter } \\
\mathrm{c}_{00}\end{array}$} & \multirow{2}{*}{$\begin{array}{c}\text { Value } \\
-0.02801\end{array}$} & \multicolumn{3}{|c|}{ 95\% Confidence Interval } \\
\hline & & -0.03554 & - & -0.02048 \\
\hline $\mathrm{c}_{10}$ & $-4.796 \mathrm{E}-05$ & $-1.710 \mathrm{E}-04$ & - & $7.504 \mathrm{E}-05$ \\
\hline $\mathrm{c}_{01}$ & 0.01637 & 0.01265 & - & 0.02009 \\
\hline $\mathrm{c}_{11}$ & $5.118 \mathrm{E}-05$ & $8.586 \mathrm{E}-06$ & - & $9.377 \mathrm{E}-05$ \\
\hline $\mathrm{c}_{02}$ & -0.002168 & -0.002723 & - & -0.001612 \\
\hline $\mathrm{c}_{12}$ & $-3.528 \mathrm{E}-06$ & $-6.599 \mathrm{E}-06$ & - & $-4.564 \mathrm{E}-07$ \\
\hline $\mathrm{c}_{03}$ & $8.393 E-05$ & $5.752 \mathrm{E}-05$ & - & $1.103 \mathrm{E}-04$ \\
\hline
\end{tabular}

with only linear terms in UV light intensity. The equation was found to fit the data with a coefficient of determination $\left(R^{2}\right)$ of 0.9934 , and $95 \%$ confidence intervals were generated for all model parameters. Additional terms to the model equation were found not to improve the overall fit to the experimental data.

\section{Acknowledgements}

This work was supported by National Aeronautics and Space Administration (NASA)—Harriett Jenkins Predoctoral Fellowship and the State of Florida through the Florida Energy Systems Consortium (FESC) funds.

\section{References}

[1] Grabowska, E., Reszczyńska, J. and Zaleska, A. (2012) Mechanism of Phenol Photodegradation in the Presence of Pure and Modified-TiO ${ }_{2}$ : A Review. Water Research, 46, 5453-5471. http://dx.doi.org/10.1016/j.watres.2012.07.048

[2] Schmidt, R.J. (2005) Industrial Catalytic Processes-Phenol Production. Applied Catalysis A: General, 280, 89-103. http://dx.doi.org/10.1016/j.apcata.2004.08.030

[3] Udom, I., Ram, M.K., Stefanakos, E.K., Hepp, A.F. and Goswami, D.Y. (2013) One Dimensional-ZnO Nanostructures: Synthesis, Properties and Environmental Applications. Materials Science in Semiconductor Processing, 16, 2070-2083. http://dx.doi.org/10.1016/j.mssp.2013.06.017

[4] Calace, N., Nardi, E., Petronio, B.M. and Pietroletti, M. (2002) Adsorption of Phenols by Papermill Sludges. Environmental Pollution, 118, 315-319. http://dx.doi.org/10.1016/S0269-7491(01)00303-7

[5] Arques, A., Amat, A.M., García-Ripoll, A. and Vicente, R. (2007) Detoxification and/or Increase of the Biodegradability of Aqueous Solutions of Dimethoate by Means of Solar Photocatalysis. Journal of Hazardous Materials, 146, 447452. http://dx.doi.org/10.1016/j.jhazmat.2007.04.046

[6] Acar, Y.B., Li, H. and Gale, R.J. (1992) Phenol Removal from Kaolinite by Electrokinetics. Journal of Geotechnical Engineering, 118, 1837-1852. http://dx.doi.org/10.1061/(ASCE)0733-9410(1992)118:11(1837)

[7] Rodgers, J.D., Jedral, W. and Bunce, N.J. (1999) Electrochemical Oxidation of Chlorinated Phenols. Environmental Science \& Technology, 33, 1453-1457. http://dx.doi.org/10.1021/es9808189

[8] Yang, G.C. and Long, Y.-W. (1999) Removal and Degradation of Phenol in a Saturated Flow by In-Situ Electrokinetic Remediation and Fenton-Like Process. Journal of Hazardous Materials, 69, 259-271. http://dx.doi.org/10.1016/S0304-3894(99)00059-X

[9] Whiteley, A.S. and Bailey, M.J. (2000) Bacterial Community Structure and Physiological State within an Industrial Phenol Bioremediation System. Applied and Environmental Microbiology, 66, 2400-2407. http://dx.doi.org/10.1128/AEM.66.6.2400-2407.2000

[10] Al-Muhtaseb, A.H., Ibrahim, K.A., Albadarin, A.B., Ali-Khashman, O., Walker, G.M. and Ahmad, M.N. (2011) Remediation of Phenol-Contaminated Water by Adsorption Using Poly(methyl Methacrylate) (PMMA). Chemical Engineering Journal, 168, 691-699. http://dx.doi.org/10.1016/j.cej.2011.01.057

[11] Riser-Roberts, E. (1998) Remediation of Petroleum Contaminated Soils: Biological, Physical, and Chemical Processes. CRC Press, Boca Raton. http://dx.doi.org/10.1201/9781420050578

[12] Pera-Titus, M., Garcia-Molina, V., Baños, M.A., Giménez, J. and Esplugas, S. (2004) Degradation of Chlorophenols 
by Means of Advanced Oxidation Processes: A General Review. Applied Catalysis B: Environmental, 47, 219-256. http://dx.doi.org/10.1016/j.apcatb.2003.09.010

[13] Rosenfeldt, E.J. and Linden, K.G. (2004) Degradation of Endocrine Disrupting Chemicals Bisphenol A, Ethinyl Estradiol, and Estradiol during UV Photolysis and Advanced Oxidation Processes. Environmental Science \& Technology, 38, 5476-5483. http://dx.doi.org/10.1021/es035413p

[14] Antonopoulou, M., Evgenidou, E., Lambropoulou, D. and Konstantinou, I. (2014) A Review on Advanced Oxidation Processes for the Removal of Taste and Odor Compounds from Aqueous Media. Water Research, 53, 215-234. http://dx.doi.org/10.1016/j.watres.2014.01.028

[15] Gupta, V.K., Jain, R., Mittal, A., Saleh, T.A., Nayak, A., Agarwal, S. and Sikarwar, S. (2012) Photo-Catalytic Degradation of Toxic Dye Amaranth on $\mathrm{TiO}_{2} / \mathrm{UV}$ in Aqueous Suspensions. Materials Science and Engineering: C, 32, 12-17. http://dx.doi.org/10.1016/j.msec.2011.08.018

[16] Devi, L.G. and Rajashekhar, K.E. (2011) A Kinetic Model Based on Non-Linear Regression Analysis Is Proposed for the Degradation of Phenol under UV/Solar Light Using Nitrogen Doped $\mathrm{TiO}_{2}$. Journal of Molecular Catalysis A: Chemical, 334, 65-76. http://dx.doi.org/10.1016/j.molcata.2010.10.025

[17] Kavitha, V. and Palanivelu, K. (2004) The Role of Ferrous Ion in Fenton and Photo-Fenton Processes for the Degradation of Phenol. Chemosphere, 55, 1235-1243. http://dx.doi.org/10.1016/j.chemosphere.2003.12.022

[18] Udom, I., Zhang Y., Ram, M.K., Stefanakos, E.K., Hepp, A.F., Elzein, R., Schlaf, R. and Goswami, D.Y. (2014) A Simple Photolytic Reactor Employing Ag-Doped ZnO Nanowires for Water Purification. Thin Solid Films, 564, 258263. http://dx.doi.org/10.1016/j.tsf.2014.05.057

[19] Shukla, P.R., Wang, S., Ang, H.M. and Tadé, M.O. (2010) Photocatalytic Oxidation of Phenolic Compounds Using Zinc Oxide and Sulphate Radicals under Artificial Solar Light. Separation and Purification Technology, 70, 338-344. http://dx.doi.org/10.1016/j.seppur.2009.10.018

[20] Pardeshi, S.K. and Patil, A.B. (2009) Effect of Morphology and Crystallite Size on Solar Photocatalytic Activity of Zinc Oxide Synthesized by Solution Free Mechanochemical Method. Journal of Molecular Catalysis A: Chemical, 308, 32-40. http://dx.doi.org/10.1016/j.molcata.2009.03.023

[21] Chiou, C.H. and Juang, R.S. (2007) Photocatalytic Degradation of Phenol in Aqueous Solutions by Pr-Doped TiO $\mathrm{Pa}_{2} \mathrm{Na}^{-}$ noparticles. Journal of Hazardous Materials, 149, 1-7. http://dx.doi.org/10.1016/j.jhazmat.2007.03.035

[22] Ollis, D.F., Pelizzetti, E. and Serpone, N. (1991) Photocatalyzed Destruction of Water Contaminants. Environmental Science \& Technology, 25, 1522-1529. http://dx.doi.org/10.1021/es00021a001

[23] Lathasree, S., Rao, A.N., SivaSankar, B., Sadasivam, V. and Rengaraj, K. (2004) Heterogeneous Photocatalytic Mineralisation of Phenols in Aqueous Solutions. Journal of Molecular Catalysis A: Chemical, 223, 101-105. http://dx.doi.org/10.1016/j.molcata.2003.08.032

[24] Akbal, F. and Onar, A.N. (2003) Photocatalytic Degradation of Phenol. Environmental Monitoring and Assessment, 83, 295-302. http://dx.doi.org/10.1023/A:1022666322436 
Scientific Research Publishing (SCIRP) is one of the largest Open Access journal publishers. It is currently publishing more than 200 open access, online, peer-reviewed journals covering a wide range of academic disciplines. SCIRP serves the worldwide academic communities and contributes to the progress and application of science with its publication.

Other selected journals from SCIRP are listed as below. Submit your manuscript to us via either submit@scirp.org or Online Submission Portal.
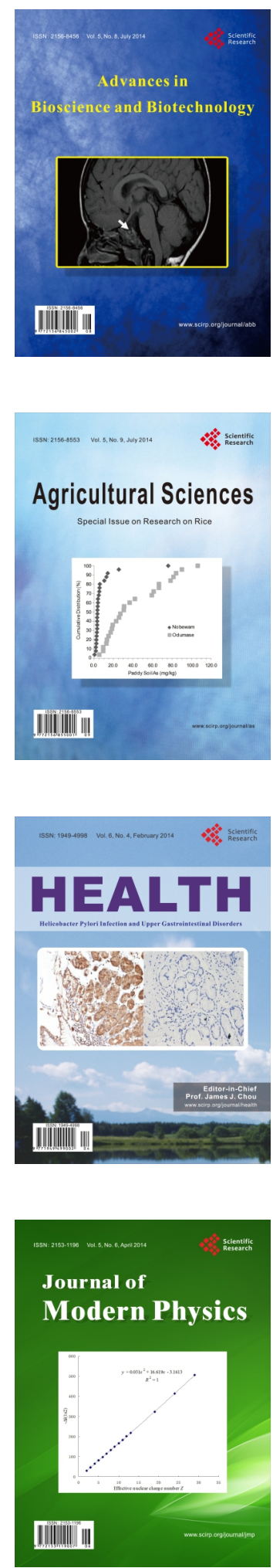
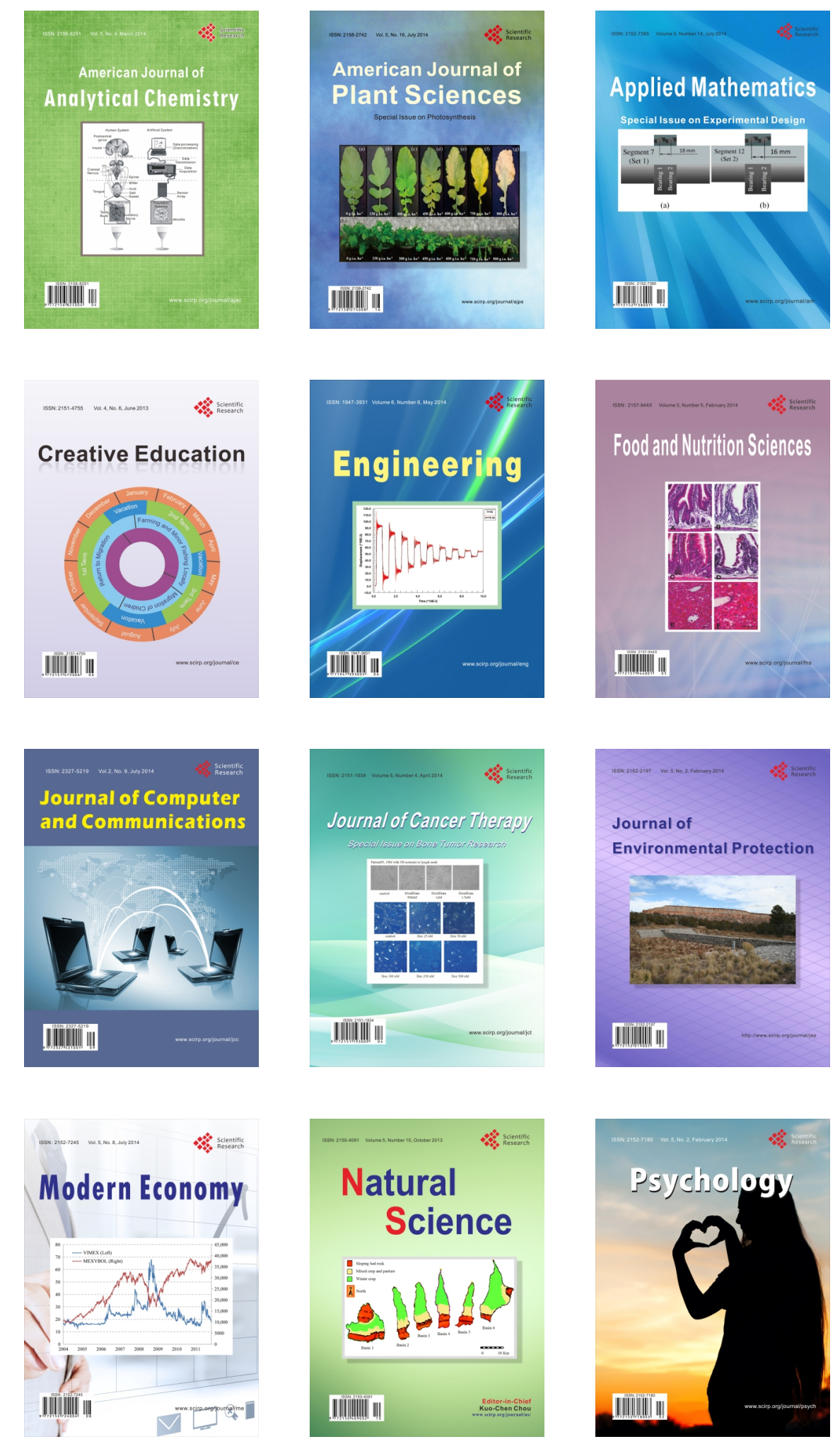